\title{
Frequency of the virilising effects of attenuated androgens reported by women with hereditary angioedema
}

\author{
Zsuzsanna Zotter, Nóra Veszeli, Dorottya Csuka, Lilian Varga and Henriette Farkas*
}

\begin{abstract}
Background: Danazol, a drug extensively used in the management of hereditary angioedema due to $\mathrm{C} 1$ inhibitor deficiency (C1-INH-HAE), has various side effects. This study investigated the virilizing actions of this drug in 31 danazol-treated female patients with HAE-C1-INH. We compared our findings with those of healthy controls and with literature data.

Methods: The patients were interviewed individually about the type and severity of the virilizing effects, as well as about their satisfaction with danazol therapy.

Results: The average duration of danazol treatment was 10.31 years [2 to 23] and its mean daily dose was $131.7 \mathrm{mg}$ [33 to 200]. The most common adverse effects were hirsutism $(n=14)$, weight gain $(n=13)$, and menstrual disturbances $(n=8)$. The severity of danazol adverse effects did not differ by duration of treatment or by daily drug dose. The mean level of patient satisfaction with the treatment was high. The comparison of age-matched healthy controls and of HAE-C1-INH patients receiving danazol did not demonstrate a statistically higher incidence of any of the monitored symptoms in the danazol group.
\end{abstract}

Conclusions: Our findings indicate that long-term danazol treatment - using the lowest effective dose - has only a mild virilizing effect.

Keywords: Hereditary angioedema, C1 inhibitor deficiency, Attenuated androgen, Danazol, Virilization, Side effect

\section{Background}

Hereditary angioedema due to $\mathrm{C} 1$ inhibitor deficiency (C1-INH-HAE) is an autosomal dominant disorder; a form of bradykinin-mediated angioedema. It is characterized by recurrent, subcutaneous, and/or submucosal edema-formation. The clinical symptoms show inter- and intraindividual variation [1]. Women with C1-INH-HAE are more likely to experience symptoms than are men [2]. Female sex hormones - estrogens, in particular - affect the synthesis of many proteins influencing the activation of the kinin-kallikrein system $[3,4]$. The management of female patients with C1-INH-HAE is similar to that of males. It comprises two stages: 1) the acute treatment of attacks, and 2) prophylaxis [3]. As regards medicinal products for long-term prophylaxis (such as antifibrinolytics,

\footnotetext{
* Correspondence: farkas.henriette@med.semmelweis-univ.hu

3rd Department of Internal Medicine, Semmelweis University, Kútvölgyi út 4, Budapest $\mathrm{H}-1125$, Hungary
}

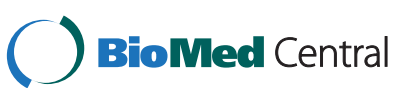

(c) 2014 Zotter et al.; licensee BioMed Central Ltd. This is an Open Access article distributed under the terms of the Creative Commons Attribution License (http://creativecommons.org/licenses/by/4.0), which permits unrestricted use, distribution, and reproduction in any medium, provided the original work is properly credited. The Creative Commons Public Domain Dedication waiver (http://creativecommons.org/publicdomain/zero/1.0/) applies to the data made available in this article unless otherwise stated. attenuated androgens [AAs], and plasma-derived C1-INH), the use of attenuated androgens in women with HAE raises a number of concerns [5]. Although the precise mode of action of AAs is unknown, these agents are thought to increase C1-INH level by stimulating hepatic synthesis, as well as by enhancing the expression of C1-INH mRNA in peripheral blood mononuclear cells [6]. The AAs also may have a potentiating effect on Aminopeptidase P, which is involved in kinin inactivation [7]. While AAs are not intended for the treatment of C1-INH-HAE, these drugs have found their way into clinical practice through empirical use. AAs are effective as prophylaxis to reduce the frequency and severity of edematous attacks in C1-INH-HAE [8]; however, their benefits should be weighed against their risks before prescription. Major side effects of AAs include hepatotoxicity, altered/pro-atherogenic lipid profile, stimulated erythropoesis, androgen-induced premature closure of the

rans 
epiphyseal plates in children, and a virilizing/androgenlike effect [9]. The latter is the primary concern in the management of female patients. Reviewing the literature, we found only a few studies evaluating the virilizing/ androgen-like effects of AAs in female patients with C1-INH-HAE [10-14]. These studies did not explore systematically the whole range of virilizing side effects, and even those that did, failed to analyze male and female patients separately - or lacked a control group. Therefore, we investigated and evaluated the frequency and severity of the possible virilizing effects of AAs in female patients with C1-INH-HAE, as well as compared our findings with the results of healthy controls and with literature data. Our study did not analyze either therapeutic efficacy, or the spectrum of other adverse events (such as altered lipid profile, hepatotoxicity, etc.), as we have published papers on these topics earlier [15-17].

\section{Patients and methods Patients}

All (31 of our 75) female patients with C1-INH-HAE (median age: 49 years; min: 20 max: 70), who were taking danazol for long-term prophylaxis participated in this survey. All subjects had been diagnosed and receiving regular follow-up care at the Hungarian Angioedema Center. In each patient, C1-INH-HAE was diagnosed according to the accepted clinical and laboratory criteria (positive family history, clinical symptoms of angioedema, low functional C1-INH level, low C4, normal C1q) [1]. At the time of the study, 16 patients with C1-INH-HAE were postmenopausal, one patient was taking an oral contraceptive (desogestrel).

After diagnosis, the patients attended follow-up visits at least once a year. A laboratory screen (including complete blood count, clinical chemistry, serum lipid profile, and liver function), abdominal sonography, and physical examination were performed on these occasions. Body weight was recorded along with the current drug regimen and dose administered, as well as the side effects experienced by the patients.

The control group consisted of 41 healthy and agematched female subjects (median age: 48 years; min: 32 max: 63). 22 of 41 were postmenopausal, 9 of them longer than 5 years, and 7 women were taking an estrogencontaining oral contraceptive. All had been referred for routine medical check-up, and volunteered for the study by giving informed consent. The healthy controls did not have any known disease (C1-INH deficiency was excluded by complement testing), or receive medicinal products at the time of blood sampling.

\section{Methods}

In our retrospective study, we compiled a list of the virilizing adverse effects of danazol by interviewing the patients, and reviewing the literature. We identified the following: menstrual disturbances (spotting, disruption of the menstrual cycle), altered libido, voice change, body hair growth (evaluated in 7 body regions by self-examination: upper lip, chin, chest, back, abdomen, thighs and legs), hypertrophy of the clitoris, increased muscle mass, reduction of breast size, acne and oily skin, weight gain, water retention, hair loss, psychological abnormalities (depression, aggressive behavior), flushing, sweating. At the follow-up visits, we provided patients with the list of all possible virilizing side effects and asked them to mark every symptom or sequel they had experienced during danazol therapy and rate their severity using the following scores: $0=$ none, $1=$ mild, $2=$ moderate, $3=$ severe. Furthermore, the patients were asked to rate the overall severity of the adverse effects (considering all types aggregately). Patient satisfaction with danazol therapy (weighing adverse effects against benefits) was rated on a Visual Analog Scale (VAS; $100 \mathrm{~mm}$ per scale). The daily dose of danazol was determined as the mean of the daily doses received during the course of therapy. During prophylaxis, we placed emphasis on administering the lowest effective dose. The 41 age-matched, healthy controls also completed the survey on the adverse events they had experienced during the last five years. The study was approved by the institutional review board of Semmelweis University of Budapest, and informed consent was obtained in accordance with the Declaration of Helsinki.

We used GraphPad Prism 6 software for statistical analysis. Spearman's correlation tests were applied to evaluate correlations. Chi-squared statistics were used to detect any significant difference among the study parameters of the HAE patients and those of the healthy controls. All the statistical analyses were two-tailed, and $\mathrm{p}<0.05$ was considered to represent a significant difference, or correlation.

\section{Results and discussion}

Thirty-one female patients with C1-INH-HAE took danazol for long-term prophylaxis. The average dose was 131.7 (min: 50, max: 200) $\mathrm{mg} /$ day. The mean duration of pre-existing danazol treatment was 10.31 (min.: 2, max.: 23) years.

The patients experienced on average 2.9 out of the 12 monitored virilizing adverse effects. Five patients did not experience any side effect whatsoever. Hirsutism $(n=14$, $42 \%$ ), weight gain ( $\mathrm{n}=13,39 \%, 10$ kilograms on average), and menstrual disturbances $(\mathrm{n}=8,26 \%)$ were the virilizing effects most commonly noted by the C1-INH-HAE patients. Table 1 shows our results in comparison with literature data, whereas Figure 1 presents the mean severity scores of the individual adverse effects. The patients rated the majority of these as mild ( 0 or 1$)$. One patient assigned a score of 3 to weight gain experienced 
Table 1 Comparison of the virilizing adverse effects of AAs among different studies

\begin{tabular}{|c|c|c|c|c|c|c|c|}
\hline & \multirow[t]{2}{*}{ Gelfand [7] } & \multirow[t]{2}{*}{ Zurlo [8] } & \multirow[t]{2}{*}{ Cicardi [9] } & \multirow[t]{2}{*}{ Sloane [10] } & \multirow[t]{2}{*}{ Bork [11] } & \multicolumn{2}{|c|}{ Our study population } \\
\hline & & & & & & Patients & Controls \\
\hline $\mathrm{N}^{\circ}$ of patients & 5 & 60 & $28(D+S)$ & $13(S)$ & $51 / 118^{*}$ & 31 & 41 \\
\hline MENSTRUAL DISTURBANCES & $100 \%$ & $79 \%$ & $50 \%(D) / 18 \%(S)$ & $23 \%$ & $76 \%$ & $26 \%$ & $38 \%$ \\
\hline ALTERED LIBIDO & & $10 \%$ & & $8 \%$ & $3 \%^{*}$ & $13 \%$ & $22 \%$ \\
\hline VOICE CHANGE & & $8 \%$ & & $8 \%$ & $14 \%^{*}$ & $19 \%$ & $10 \%$ \\
\hline HAIR GROWTH & & $12 \%$ & & & $19^{*}$ & $42 \%$ & $37 \%$ \\
\hline CLITORIS ENLARGEMENT & & & & & $12 \%$ & $3 \%$ & $0 \%$ \\
\hline INCREASED MUSCLE MASS & & $2 \%$ & & & $3 \%^{*}$ & $13 \%$ & $7 \%$ \\
\hline BREAST SIZE & & & & & $12 \%$ & $16 \%$ & n.a." \\
\hline ACNE/OILY SKIN & & $8 \%$ & & $8 \%$ & $9^{*}$ & $19 \%$ & $12 \%$ \\
\hline WEIGHT GAIN & $100 \%$ & $60 \%$ & $28 \%(D) / 17 \%(S)$ & $1 \%$ & $42 \% *$ & $39 \%$ & $59 \%$ \\
\hline WATER RETENTION & & $2 \%$ & & & & $6 \%$ & $29 \%^{+}$ \\
\hline HAIR LOSS & & $18 \%$ & & & & $19 \%$ & $27 \%$ \\
\hline PSYCHOLOGICAL ABNORMALITIES & & $2 \%$ & & $0 \%$ & $11 \% *$ & $16 \%$ & $46 \%^{+}$ \\
\hline $\begin{array}{l}\text { Discontinuation/continuation of } \\
\text { danazol therapy }\end{array}$ & Continued & $16 \%$ discontinued & $\begin{array}{l}\text { The vast majority } \\
\text { of patients } \\
\text { continued therapy }\end{array}$ & $\begin{array}{l}\text { No interruption } \\
\text { of stanozolol } \\
\text { therapy }\end{array}$ & $\begin{array}{l}\text { No interruption } \\
\text { of stanozolol } \\
\text { therapy }\end{array}$ & $\begin{array}{l}\text { No interruption } \\
\text { of danazol } \\
\text { therapy }\end{array}$ & \\
\hline
\end{tabular}

Although we would have preferred specifying the absolute numbers of patients, this was not feasible, because not all the authors provided this information. Therefore, all values are expressed as percentages, for the sake of comparability. References are reported in brackets.

$\mathrm{D}=$ danazol, $\mathrm{S}=$ stanazolol, $^{*}=$ total HAE population (The properties were evaluated both in males and in females), ${ }^{\dagger}=\mathrm{p}<0.05,{ }^{\#} \mathrm{n} . \mathrm{a}=\mathrm{Half}$ of the women did not answer this one, or gave information on the elasticity of their breasts.

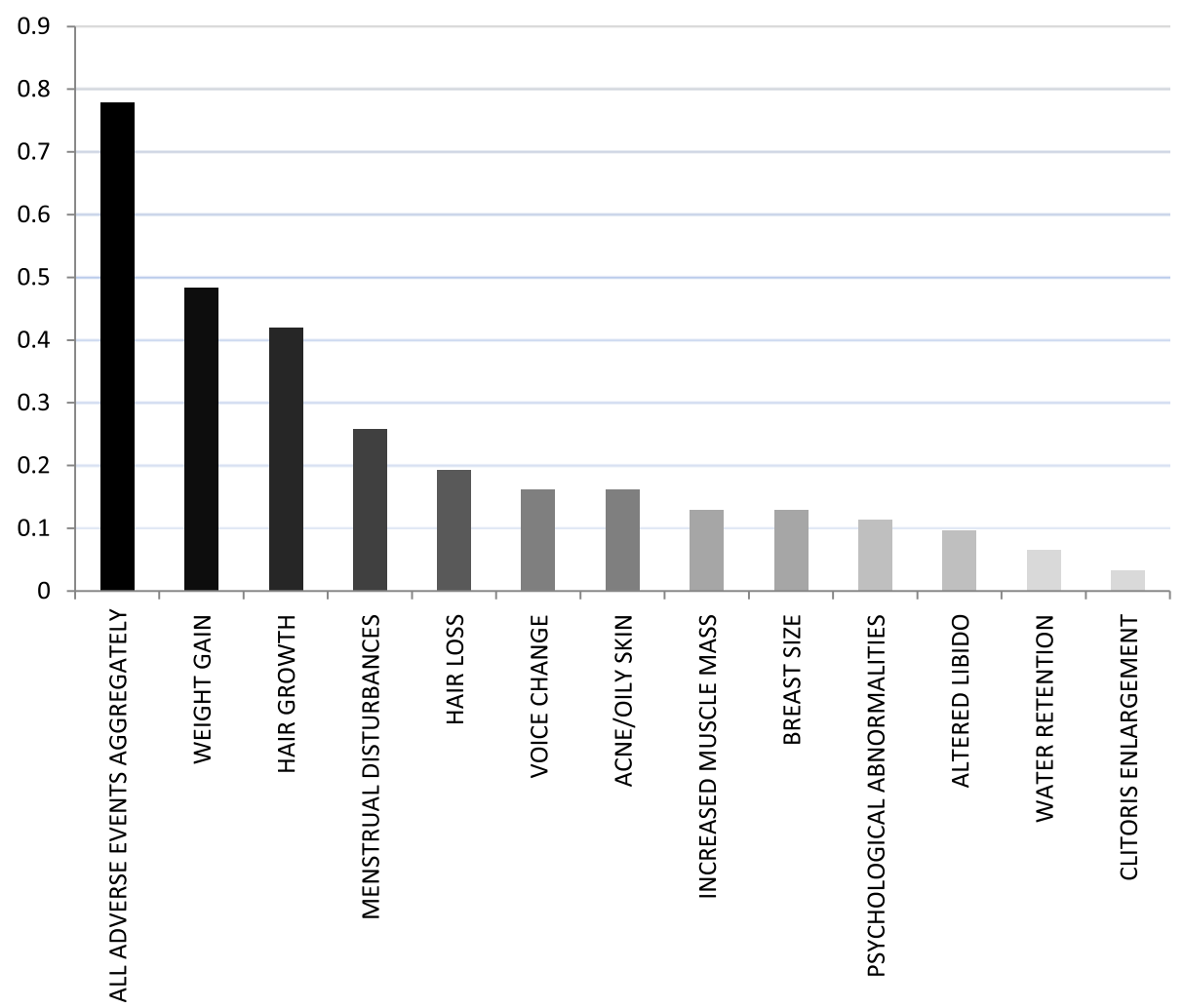

Figure 1 The severity scores of each and all adverse events, ranked by severity on a 3-grade scale. 
as an adverse effect, and two additional patients rated hair growth and menstrual disturbances with a score of 2 .

The mean score reflecting the overall severity of the side effects was 0.7 (min.: 0, max.: 3; see Figure 1). The Spearman's test did not reveal a significant correlation between the overall severity score of adverse effects and the duration of treatment $(\mathrm{p}=0.599)$, or the daily dose of danazol $(p=0.204)$.

Analyzing the most common and most severe adverse effect separately with Spearman's test, we could not detect any significant correlation between the patients' BMI and danazol dose $(\mathrm{p}=0.671)$. We found a significant, positive relationship between the patients' BMI and the duration of treatment $(\mathrm{p}=0.031)$. The change in body weight did not correlate with either the dose $(\mathrm{p}=0.818)$, or with the duration of danazol treatment. Menstrual disturbances occurred in 8 patients. Six of these patients discontinued danazol (because they wanted to have a child) and their menstrual cycles became regular again.

The mean score (VAS, $100 \mathrm{~mm}$ per scale) of patient satisfaction was 84 (min.: 30 , max.: 100). None of the patients discontinued danazol treatment due to virilizing adverse events. The Pearson's test did not detect any significant correlation between patient satisfaction with danazol and the duration of treatment, or the daily drug dose.

Comparing female HAE patients with their age-matched, healthy controls, we did not detect a statistically significant difference in the majority of the study parameters. Water retention and psychological abnormalities were exceptions, as their incidence was statistically higher in the control group than among the patients $(29 \%$ vs. $6 \%$, $\mathrm{p}=0.0177$; and $46 \% v s .16 \%, \mathrm{p}=0.011$, respectively).

Our findings indicate that long-term treatment with the lowest effective dose of danazol has only a mild virilizing effect, because the patients experienced three on average out of the 12 monitored adverse events. The severity of the virilizing adverse effects (scored in the range from 0 to 3 ) was below 0.5 in all instances, and the overall score was as low as 0.7 for the whole study population. Of note, the mean age of our patients was in the age range when menopause usually occurs - thus, these adverse effects might even have resulted from spontaneous proandrogenic events. In agreement with literature data, the most common adverse effects included hirsutism, weight gain, and menstrual disturbances (Table 1). Weight gain has not yet been demonstrated to be a direct consequence of treatment with AAs, although we found that the longer the duration of treatment, the higher the body mass index of the female patients. However, the magnitude of the change in body weight did not correlate with any of the above parameters. Hirsutism occurred more commonly than in the other studies, but its frequency did not exceed that seen in the Hungarian general population, as well as it was of mild severity. Menstruation disturbances were common but reversible and resolved after AAs had been discontinued; this is also in agreement with the observations published in the literature.

Many authors emphasized that these adverse effects are dose-related $[14,18,19]$. We could not demonstrate this relationship in our study, because our patients were taking relatively low doses. Nevertheless, this observation further supports the practice of administering the lowest effective dose to prevent side effects. Discontinuing prophylactic treatment because of the virilizing effect of danazol was not necessary in any of our patients. This matches the experience of other authors, who have found that only a small proportion of patients had to stop taking danazol due to its virilizing effect [12-14].

The reports available on the virilizing adverse effects of danazol indicate that these events commonly occur in women taking this medicinal product. However, this does not necessarily mean that these side effects are severe. In our study population, the severity scores of the adverse events consistently remained below the 'mild' rating possibly, because we had administered average or lower doses. To date, the studies published in the literature reported the incidence of adverse events without analyzing their severity. This might explain the incongruity between the abundance of virilizing adverse effects attributed to danazol, and the small number of patients who discontinue treatment because of these events (mostly those receiving higher doses). Further, a causal relationship between treatment with danazol and the occurrence of virilizing adverse effects cannot be established with certainty, because the difference compared with the healthy population was not statistically significant. In view of the patients' age, these symptoms might even be attributable to the menopause.

\section{Conclusion}

The virilizing effects of AAs are mild at the lowest effective dose not to exceed $200 \mathrm{mg}$. State-of-the-art medicinal products with known mechanisms of action, as well as with confirmed efficacy and safety have become available (such as plasma-derived nanofiltered C1-INH concentrate - Cinryze) [20]. Other alternatives (for example recombinant human $\mathrm{C} 1-\mathrm{INH})$ for prophylaxis are also under investigation [21]. Notwithstanding this, treatment with attenuated androgens is considered an alternative for prophylaxis. These agents are administered by the oral route, which is convenient for the patients and economical for the health service provider. The occurrence of adverse effects can be prevented or their timely recognition is feasible through regular follow-up at least once a year $[22,23]$. Further, novel therapeutic options are not yet available in many countries. Therefore, abandoning treatment with AAs is not yet possible, because in many countries, these drugs offer the only therapeutic option for severe cases. 


\section{Abbreviations}

HAE: Hereditary angioedema; C1-INH: C1-Inhibitor; C1-INH-HAE: Hereditary angioedema due to C1-inhibitor deficiency; AAs: Attenuated androgens; VAS: Visual analogue scale.

\section{Competing interests}

Henriette Farkas has received consultancy/speaker fees and honoraria from Shire Human Genetic Therapies Inc., Swedish Orphan Biovitrum, and CSL Behring. Dorottya Csuka has received travel grants from CSL Behring, Shire Human Genetic Therapies Inc, and Viropharma. Lilian Varga has received travel grants from CSL Behring, and Shire Human Genetic Therapies Inc.

\section{Authors' contributions}

ZZ: conception and design of the study; data generation; analysis and interpretation of the data and preparation or critical revision of the manuscript. NV: data generation; analysis and interpretation of the data and preparation or critical revision of the manuscript. DC: data generation; analysis and interpretation of the data and preparation or critical revision of the manuscript. LV: conception and design of the study; analysis and interpretation of the data and preparation or critical revision of the manuscript. HF: conception and design of the study; data generation; analysis and interpretation of the data and preparation or critical revision of the manuscript. All authors read and approved the final manuscript.

Received: 23 September 2014 Accepted: 27 November 2014 Published online: 05 December 2014

\section{References}

1. Cicardi M, Aberer W, Banerji A, Bas M, Bernstein JA, Bork K, Caballero T, Farkas H, Grumach A, Kaplan AP, Riedl MA, Triggiani M, Zanichelli A, Zuraw $\mathrm{B}, \mathrm{HAWK}$ under the patronage of EAACl (European Academy of Allergy and Clinical Immunology): Classification, diagnosis, and approach to treatment for angioedema: consensus report from the Hereditary Angioedema International Working Group. Allergy 2014, 69:602-616.

2. Bork K, Meng G, Staubach P, Hardt J: Hereditary angioedema: new findings concerning symptoms, affected organs, and course. Am J Med 2006, 119:267-274

3. Farkas $\mathrm{H}$ : Current pharmacotherapy of bradykinin-mediated angioedema. Expert Opin Pharmacother 2013, 14:571-586.

4. Frank MM, Gelfand JA, Atkinson JP: Hereditary angioedema: the clinical syndrome and its management. Ann Intern Med 1976, 84:580-593.

5. Bouillet $L$, Longhurst $H$, Boccon-Gibod I, Bork K, Bucher C, Bygum A, Caballero T, Drouet C, Farkas H, Massot C, Nielsen EW, Ponard D, Cicardi M: Disease expression in women with hereditary angioedema. Am J Obstet Gynecol 2008, 199:484. e481-484.

6. Pappalardo E, Zingale LC, Cicardi M: Increased expression of C1-inhibitor mRNA in patients with hereditary angioedema treated with Danazol. Immunol Lett 2003, 86:271-276.

7. Drouet C, Désormeaux A, Robillard J, Ponard D, Bouillet L, Martin L, Kanny G, Moneret-Vautrin DA, Bosson JL, Quesada JL, López-Trascasa M, Adam A: Metallopeptidase activities in hereditary angioedema: effect of androgen prophylaxis on plasma aminopeptidase P. J Allergy Clin Immunol 2008, 121:429-433.

8. Fust G, Farkas H, Csuka D, Varga L, Bork K: Long-term efficacy of danazol treatment in hereditary angioedema. Eur J Clin Invest 2011, 41:256-262.

9. Shahidi NT: A review of the chemistry, biological action, and clinical applications of anabolic-androgenic steroids. Clin Ther 2001, 23:1355-1390

10. Gelfand JA, Sherins RJ, Alling DW, Frank MM: Treatment of hereditary angioedema with danazol. Reversal of clinical and biochemical abnormalities. N Engl J Med 1976, 295:1444-1448.

11. Zurlo JJ, Frank MM: The long-term safety of danazol in women with hereditary angioedema. Fertil Steril 1990, 54:64-72

12. Cicardi M, Castelli R, Zingale LC, Agostoni A: Side effects of long-term prophylaxis with attenuated androgens in hereditary angioedema: comparison of treated and untreated patients. J Allergy Clin Immunol 1997, 99:194-196.

13. Sloane DE, Lee CW, Sheffer AL: Hereditary angioedema: Safety of long-term stanozolol therapy. J Allergy Clin Immunol 2007, 120:654-658.

14. Bork K, Bygum A, Hardt J: Benefits and risks of danazol in hereditary angioedema: a long-term survey of 118 patients. Ann Allergy Asthma Immunol 2008, 100:153-161.
15. Farkas H, Czaller I, Csuka D, Vas A, Valentin S, Varga L, Széplaki G, Jakab L, Füst G, Prohászka Z, Harmat G, Visy B, Karádi I: The effect of long-term danazol prophylaxis on liver function in hereditary angioedema-a I ongitudinal study. Eur J Clin Pharmacol 2010, 66:419-426.

16. Szegedi R, Szeplaki G, Varga L, Prohaszka Z, Szeplaki Z, Karadi I, Fust G, Farkas H: Long-term danazol prophylaxis does not lead to increased carotid intima-media thickness in hereditary angioedema patients. Atherosclerosis 2008, 198:184-191.

17. Szeplaki G, Varga L, Valentin S, Kleiber M, Karadi I, Romics L, Fust G, Farkas H: Adverse effects of danazol prophylaxis on the lipid profiles of patients with hereditary angioedema. J Allergy Clin Immunol 2005, 115:864-869.

18. Zuraw BL: Hereditary angiodema: a current state-of-the-art review, IV: short- and long-term treatment of hereditary angioedema: out with the old and in with the new? Ann Allergy Asthma Immunol 2008, 100:S13-S18.

19. Cicardi M, Bergamaschini L, Cugno M, Hack E, Agostoni G, Agostoni A Long-term treatment of hereditary angioedema with attenuated androgens: a survey of a 13-year experience. J Allergy Clin Immunol 1991, 87:768-773

20. Zuraw BL, Busse PJ, White M, Jacobs J, Lumry W, Baker J, Craig T, Grant JA, Hurewitz D, Bielory L, Cartwright WE, Koleilat M, Ryan W, Schaefer O, Manning M, Patel P, Bernstein JA, Friedman RA, Wilkinson R, Tanner D, Kohler G, Gunther G, Levy R, McClellan J, Redhead J, Guss D, Heyman E, Blumenstein BA, Kalfus I, Frank MM: Nanofiltered C1 inhibitor concentrate for treatment of hereditary angioedema. N Engl J Med 2010, 363:513-522.

21. Porebski G, Reshef A, Moldovan D: The prophylaxis of hereditary angioedema attacks with recombinant human C1 inhibitor: who will take advantage of the individualized treatment approach? Allergy 2013, 68:1207-1209.

22. Bowen T, Cicardi M, Farkas H, Bork K, Longhurst HJ, Zuraw B, AygoerenPürsün E, Craig T, Binkley K, Hebert J, Ritchie B, Bouillet L, Betschel S, Cogar D, Dean J, Devaraj R, Hamed A, Kamra P, Keith PK, Lacuesta G, Leith E, Lyons H, Mace S, Mako B, Neurath D, Poon MC, Rivard GE, Schellenberg R, Rowan D, Rowe A, et al: 2010 International consensus algorithm for the diagnosis, therapy and management of hereditary angioedema. Allergy Asthma Clin Immunol 2010, 6:24.

23. Craig T, Aygören-Pürsün E, Bork K, Bowen T, Boysen H, Farkas H, Grumach A, Katelaris $\mathrm{CH}$, Lockey $\mathrm{R}$, Longhurst $\mathrm{H}$, Lumry W, Magerl M, Martinez-Saguer I, Ritchie B, Nast A, Pawankar R, Zuraw B, Maurer M: WAO Guideline for the Management of Hereditary Angioedema. World Allergy Organ J 2012, 5:182-199.

\section{doi:10.1186/s13023-014-0205-6}

Cite this article as: Zotter et al:: Frequency of the virilising effects of attenuated androgens reported by women with hereditary angioedema. Orphanet Journal of Rare Diseases 2014 9:205.

\section{Submit your next manuscript to BioMed Central and take full advantage of:}

- Convenient online submission

- Thorough peer review

- No space constraints or color figure charges

- Immediate publication on acceptance

- Inclusion in PubMed, CAS, Scopus and Google Scholar

- Research which is freely available for redistribution 